\title{
The Macropolitics of Microsound: Gender and sexual identities in Barry Truax's Song of Songs
}

\author{
DANIELLE SOFER \\ Department of Music, Room 115 Logic House, Maynooth University, Maynooth, County Kildare, Ireland \\ Email: daniellessofer@gmail.com
}

\begin{abstract}
This analysis explores how Barry Truax's Song of Songs (1992) for oboe d'amore, English horn and two digital soundtracks reorients prevailing norms of sexuality by playing with musical associations and aural conventions of how gender sounds. The work sets the erotic dialogue between King Solomon and Shulamite from the biblical Song of Solomon text. On the soundtracks we hear a Christian monk's song, environmental sounds (birds, cicadas and bells), and two speakers who recite the biblical text in its entirety preserving the gendered pronouns of the original. By attending to established gender norms, Truax confirms the identity of each speaker, such that the speakers seemingly address one another as a duet, but the woman also addresses a female lover and the man a male. These gender categories are then progressively blurred with granular time-stretching and harmonisation (which transform the timbre of the voices), techniques that, together, resituate the presumed heteronormative text within a diverse constellation of possible sexual orientations.
\end{abstract}

\section{INTRODUCTION}

Almost thirty years ago, Canadian composer Barry Truax (b. 1947) explained how significantly granular synthesis had informed his approach to musical composition. Despite concerning itself with 'the seemingly trivial grain', granular synthesis not only changed how he conceived of the greater processes of musical composition, but also changed the way he thought of music and its larger social and historical function (1990: 123, 132). The practice, as it turns out, concerns the musically global as much as the minute, '[it] clearly juxtaposes the micro and macro levels, as the richness of the latter lies in stark contrast to the insignificance of the former' (ibid.: 123). Musical relationships forming the 'inner complexity' of the work, he says, are necessarily shaped by 'their possible relationships to the environment or society at large' (Truax 2012), what he terms the music's 'outer complexity'.

As a researcher working with R. Murray Schafer, Barry Truax groups himself within the soundscape composition' movement, a compositional approach that combines 'artistic creativity with social concerns' (ibid.: 193). But he has gradually extended the broad soundscape philosophy, which sometimes risks overly 'aestheticising the sounds of the environment', to consider what he calls 'context-based composition' (Truax 1996, 2000,
2001, 2008, 2012), a more accurate description of how his homoerotic compositions fit into the socio-historical context in which they are situated (Truax 2003). Whereas soundscape composition often maintains the recognisability of a sound's source so as to refer to the real world, many of Truax's context-based compositions begin by introducing referential sounds like the voice or the environmental sounds of animals and insects only to modify these sounds gradually with digital processing. In this way, the composer encourages his listeners to relate recognisable sources to heavily processed and often unrecognisable results; in short, inexperienced listeners need to learn to listen acousmatically (Truax 1994a: 186; 2000: 125). Truax explained this compositional orientation in the Call for Submissions to this issue: 'A key distinguishing feature of context-based composition appears to be that real-world contexts inform the design and composition of aurally based work at every level, that is, in the materials, their organisation, and ultimately the work's placement within cultural contexts' Thus sound itself becomes entrenched, and, indeed, drenched with context at every register, engaging not just with contexts extrinsic to the work, but insisting and relying on trans-contextual knowledge. 'Perhaps most significantly', reads Truax's Call for Submissions, 'listeners are encouraged to bring their knowledge of real world contexts into their participation with these works.' In context-based composition, musical structure is defined by parameters that extend beyond the 'purely' formal to such structuring parameters as gender and sexuality, for instance, if one looks to Barry Truax's many compositions.

Truax's Song of Songs (1992) for oboe d'amore, English horn and two digital soundtracks is one example of context-based composition. ${ }^{1}$ More specifically, it is a piece that references gender and sexuality

\footnotetext{
${ }^{1}$ The oboe d'amore and English horn on the recording (Truax 1994b) are played by Lawrence Cherney, who also commissioned the work for Soundstreams. Computer graphic images were designed by Theo Goldberg. The CD's cover features one of these images. The score is available at the composer's website www.sfu.ca/ truax/songs.html; and the composer has made the complete documentation of the piece, including source sounds, processing, production score, live score and spectrograms available on the Documentation DVDROM (Truax 2010). I thank Barry Truax for providing me with all these materials.
} 
at several registers - text, music, meaning, social and historical context - moving beyond such binary categories as the male and female genders or homo- and heterosexual orientations to a more fluid and dynamic understanding of gender and sexuality. The sounds on the two soundtracks of Song of Songs - the voices of two speakers (one male, one female), a singing monk and environmental sounds from birds, bells, crickets, cicadas, flowing water and a burning fire - are all subjected in varying degrees to the technique known as timestretching to shift a sound's time scale without varying its frequency. In Song of Songs, time-stretching is used to modify the rhythm of the spoken text subtly to make it more 'song-like' (Truax 2003: 119), and, as I show later, when accompanied by harmonisation, the technique prolongs sounds into sustained timbral textures.

In the opening material of the piece Truax interferes with the samples minimally in order to retain the sonic identities of the voices. The voices of the two speakers, the man, recited by Norbert Ruebsaat, and the woman, recited by Thecla Schiphorst, are therefore arguably already from the beginning identifiable with their representative genders. By having both speakers recite the same portions of the biblical text of the Song of Songs, without altering the gendered pronouns of the original text, the composer gives the male and female speakers the opportunity in the beginning of the piece to address either their respective opposite- or same- gender lovers. ${ }^{2}$ While the speakers in Song of Songs are introduced within the recognisable pitch range and timbre attributed to their respective genders (more on this later), as the piece progresses the voices are often time-stretched or harmonised, such that the role of the voice is changed. The voices of the speakers sometimes sound ambiguously gendered, as if spoken through a vocoder, and, in more extreme cases, the voices are stretched and filtered so far out of proportion that they are hardly recognisable as voices and may at times even be heard as sustained environmental ambiences setting the contextual scenery for the music in addition to the voice's more conventional solo performing role. The following analysis explores the normative gender categories listeners are likely to assign to the voices they first hear in the opening of the piece. The analysis then provides examples to demonstrate instances in the piece in which gender 'blurring' identified by the composer occurs (Truax 2003: 119). The final section of the article situates Song of Songs within its contemporaneous musical climate through a comparison to Susan McClary's (2002) wellknown analysis of Laurie Anderson's $O$ Superman, which also provides some context for how theories of

${ }^{2}$ The complete text is available on the composer's website, Barry Truax, Song of Songs, www.sfu.ca/ truax/songtxt.html (accessed 14 March 2016). In an interview I conducted with Barry Truax on 12 June 2014 in Berlin, the composer informed me that the text was adapted from the King James translation of the Bible. gender and sexuality may have informed Truax's compositional approach.

\section{GENDER AND THE VOICE}

Although biological sex is determined primarily by physiology, this physiological factor is not immediately apparent in the realm of electroacoustic music. And yet, vocal music nevertheless clings to gender, whether we attend to it as meaningful for a given analytical orientation or not. In their introduction to Embodied Voices, editors Leslie C. Dunn and Nancy A. Jones (1994) compare feminist uses of the term 'voice', as a metaphor for women's historical and political struggle to be heard, with non-verbal 'vocality' as the literal and sonorous expression referred to in Roland Barthes's (1977) notion 'the grain of the voice'. Dunn and Jones's term 'embodiment' adjoins these two meanings to emphasise 'the performative dimension of vocal expression ... [its] dynamic, contingent quality'. The embodied voice thus functions as the 'material link between "inside" and "outside", self and other ... [And] since both language and society are structured by codes of sexual difference, both the body and its voice are inescapably gendered' (Dunn and Jones 1994: 1-2). The female voice has often been used in reference to the female body - think, for example, of the enticing sirens in Homer's Odyssey (Cavarero 2005: 106-7; Peraino 2006: 1-67). Barbara Bradby (1993) has addressed links between 'gender, technology, and the body' in electronic (dance) music to show how the female voice can be used to represent a distorted female perspective compromised by the auspices of 'male fantasy' - by the gaze of the (male) producer or composer (ibid.: 158). In this regard, a monumental study by Hannah Bosma (2003) expanded Bradby's findings into the electroacoustic realm, showing the prevalence in 'electrovocal' music of partnerships between male composers and female vocalists. Bosma observed in these ubiquitous partnerships that the female voice is often attached to a conjured image of the female body, arguing therefore that 'gendered voices' have a 'symbolic significance' on account of their reflexive embodiment (ibid.: 12).

Gender not only shapes the manner in which we intuit bodies individually, but, according to critical theorist Eve Kosofsky Sedgwick (1990), it is also the primary means by which we explore relations between and among bodies. Sedgwick perceives gender (and not age, physical appearance, ability, sensation, frequency of behaviour, species, etc.) as the most dominant dimension by which sexual orientation is determined in contemporary Western society (ibid.: 8). Electroacoustic music, however, does not easily resolve itself to reductive gender determinations, since, without visually accompanying evidence of the female body or the recognition of the performer's name or identity, it is not always clear if the represented figure is indeed a 
woman (Bosma 2013: 54). The disembodied voice presents ambiguously, particularly in the slippery categories of identity and orientation. As Judith Butler notes, '[gender] identity [i]s a compelling illusion, an object of belief (1988: 520), and in the case of electroacoustic music, the voice is at the heart of this illusion. When the voice is recognisable as such, a question as to whether the voice references its originating speaking body still lingers. If I recognise the voice at all, it is likely that I will attempt to understand, categorise, and parse it, whether I do this consciously or unconsciously (Emmerson 2007: 14-16). Though, given digital processing, I may never successfully identify its source or cause.

When it comes to the acousmatic voice there seem to be two competing, though not absolutely exclusionary, theories: the first being that, once recorded, the voice no longer serves as a referent to its original source and cause, to its originating body (Kane 2014: 223-6); and the second that the voice can never be disembodied. Advancing this second theory, Steven Connor (2012) declares 'dissociated voices always [seem] to summon in their wake a phantasm of some originating body, effect convening cause' (see also Connor 2000: 353). In the first case, it is tempting to explain the recorded voice as a sound 'object', whose identity is open and unrestricted by the delimiting categories that organise actual bodies. And yet, a position that does not account for such identifying factors as gender, however optimistic, potentially relies on a myth of music's absolutism, therefore perpetuating the long-standing resistance by some to acknowledge that context might not arise entirely from 'music's inner relationships' (Truax 1994a: 177). The second case, the opinion that the voice is never disembodied, implicitly accepts that we retain gender and sexual markers as structuring determinants even when no body is visible. But with this view there is still a risk in insisting on the 'phantasm of some originating body', to recall Connor's description. Maintaining that the voice is always embodied presumes that gender categories are alwaysalready inherited into the acousmatic context, thereby precluding voices from potentially sliding from one gender to another or anywhere in between, a fluidity of identity not easily attained with actual bodies (either in the real world or in performance), but commonly encountered electroacoustically. Truax's solution is to negotiate the territory between voice recognition and denial of its referential significance constantly. In this way, relationships develop between the voices and the personae they are perceived to embody as well as between the other musical and environmental sounds common to his pieces.

Despite the frequency with which electroacoustic composers employ the gendered voice towards erotic ends (famous examples are Schaeffer and Henry's 'Erotica' movement from Symphonie pour un homme seul (1949-50), Berio's Visage (1961) and Takemitsu's Vocalism Ai (Love) (1956/64)), few aside from Truax explore erotic significance outside the confines of normative heterosexuality. ${ }^{3}$ In 'Homoeroticism and Electroacoustic Music: Absence and Personal Voice', Truax writes, 'Art is said to mirror society, but if you look in the mirror and see no reflection, then the implicit message is that you don't exist' (2003: 119). The composer therefore makes an effort to find representative ways of including minority identities primarily gender and sexual identities - to amend their habitual absence from the electroacoustic music tradition. Many of Truax's works exhibit the composer's acknowledged 'homoerotic' representations, these include Androgyny (1978), Androgyne, Mon Amour (1996-7) after Tennessee Williams's poems, Twin Souls (1997), several pieces on the theme Powers of Two (1995-9) including an operatic version (2004), and Skin \& Metal (2004). In many pieces, Truax's samples undergo digital 'transformations', a term composer and electroacoustic theorist Denis Smalley discusses at length in the context of electroacoustic music. 'Transformations', says Smalley, 'concern changes in the state of sonic identity ... A transformation may be regarded as travelling a certain distance from its base, and the type of change may be defined in terms of its direction - whether the source-cause implications are specific, implied or free' (Smalley 1993: 279).

Given these transformative possibilities, I have chosen to focus on Song of Songs as an example that explores a wider spectrum of gender and sexual representations than the homoerotic perspective Truax explicitly mentions in his article. In this article, I take listener perceptions of gender and sexuality in electroacoustic music as context-dependent criteria, meaning that notions of gender and sexual orientation depend as much on the processes by which a piece is composed as on a contemporary understanding of gender - both contemporaneously to the work's composition and, separately, to its hearing. With supporting evidence from psychoacoustics and empirical studies, I consider the inheritance of gender and sexuality within a genre of music often represented historically as devoid of bodily markers.

\section{TEXTUAL CONSIDERATIONS}

Of the many sensuous moments recorded in the Bible, King Solomon's Song of Songs is probably the longest, detailed and most celebrated portion. Remarkably, two thousand years after the scripture was first recorded in the second century CE, Solomon and Shulamite's mutual desires continue to be recognisable to us today. Their love is described in vague enough terms to still be

${ }^{3}$ For a representative list of erotic electroacoustic works, see Sofer (2016: 231). 
relevant, while the specifics of the story - the lovers' mutual descriptions of one another's physical bodies, their movements and even details of their environment - remain alluring for new interpretations. The Song of Songs is commonly interpreted in one of two ways. It can be read literally as a dialogue between King Solomon and his lover Shulamite, the two named characters in the poems, or in a metaphorical reading (the typical religious interpretation), as a dialogue between God and the people of Israel. Identifying the characters one way or another of course changes what relationship we perceive between them, whether romantic love or mere companionship, and this is without mentioning alternative levels of meaning yielded by retaining both the metaphorical and the literal narratives as viable interpretive registers (Carr 2000).

There is much to suggest that these songs depict erotic desire beyond mere companionship, as, for example, in many physically descriptive passages, 'thy stature is like to a palm tree, and thy breasts to clusters of grapes' or 'I sat down, under his shadow, and his fruit was sweet to my taste'. Song of Songs expert Michael V. Fox convincingly disputes a singularly metaphorical interpretation, arguing that metaphorical poetry from this time typically speaks of 'love in generalities', whereas the firstperson accounts in the Songs read more like personal testimony (Fox 1985: 296). Although the characters sometimes refer to one another in the third person out of respect, they often also refer directly each to the other, something uniquely intimate for texts from this period. But Fox warns against interpretations that distort the text's palpable allure by overemphasising its anatomical symbolism (ibid.: 299). Love in the Songs is an orientation towards a lover, 'It is mainly the presence or absence of the beloved, or the expectation of that presence, that determines what effects love will work' (ibid.: 323). And so, although only two characters are named, Fox suggests that one can read multiple personae in this text in addition to the named man and woman (ibid.: 255). Likewise, attempts to unveil the voices in Truax's pieceto reconcile the voices with real world sources and causes - oversimplify the complex identities evoked in the work. Truax's setting exploits the text's multitude of possible voices, employing various 'blurring' effects to expand the meaning of love through metaphor (2003: 119). As Truax sees it, electroacoustic composition is an ideal setting for a sexually explicit engagement with sound precisely because of the ambiguity of attempting to recognise sound sources. This ambiguity allows for flexible relations to form among and between elements, people and things.

Song of Songs is in four movements titled after times of day suggested in the text the piece sets, and each movement features sounds characteristic to the time of day indicated by that movement's title. Monastery bells and a monk's song sound in the 'Morning', and the hazy 'Afternoon' is adorned with the seasonal charms of singing cicadas. As 'Evening' descends and the heat disperses, crackling fires create a perfect setting for amorous activities. In 'Night and Daybreak', a canopy of chirping crickets first beckons sleep and another day dawns at the familiar tolling of the bell from the work's opening.

The daily cycle is apparent not only in explicit references to morning in the first song or in lines like 'until the day break and the shadows flee away' to signify evening and daybreak in the third and fourth movements, but also in the speakers' more subtle allusions to their environment - references to shadows, light, sun, flowers and insects - indicating times of day or the season and in the composer's organisation of the text emphasises these environmental references. By structuring the sonic environment according to textual descriptions, Truax ensures that the sounds 'themselves' are inextricable from the overlapping intimacy conveyed linguistically by the adoring lovers. Like the warm memories invoked in the unaccompanied saetas of Federico García Lorca's (homo)erotic poem 'Before the Dawn', Truax's environmental sounds convey several levels of familiarity. Truax's 'Evening' recalls Lorca's forbidden 'green hour', the time when out-ofsight lovers cast all rules and social expectations to the wind to unite briefly in hidden bliss. 'But like love / the archers are blind', writes Lorca, and in stride, Truax arouses erotic connotations but grants his listeners their own particular associations.

\section{VOCAL QUALITY AND IDENTITY}

Truax is an electroacoustic composer who, since the 1980s, has worked extensively with the granulation of sampled sound (Truax 1985, 1988). Granular synthesis, as it is more commonly called, affords a process of time-stretching. The grains are not merely extracted from the source material, but are manipulated according to the flexibility afforded by the time scale. Notably, this temporal flux also contributes to perceived differences in timbre; Truax (n.d.) notes that the time-shifting he introduced in The Wings of Nike (1987) and developed further in Song of Songs '[prolongs] the sounds into sustained timbral textures', which allow listeners to engage more closely with sound. Granular time-stretching is one manner by which Truax 'magnifies' sound. Using a short fixed sample, he introduces grains in the same order as they sound in the originating sample, but staggers overlapping grains to deliberately extend their offsets (the point from which the sample begins to play) and smooth out their envelopes so as to give the impression of the sound in slow motion. Even if, for example, two adjacent grains are of the same aural quality, source and envelope, one's perception of how a sound unfolds in time depends on how the reintroduced grains are 
staggered in relation to one another. The dragging effect is not merely acoustic, but extends also to any meaning listeners may attribute to a sound. More specifically, when applied to a recognisable voice, the technique affects the quality of that voice and hence the listener's perception of it.

All the recorded sounds on the two soundtracks every sound in Song of Songs except the live oboe d'amore and English horn - undergo time-stretching (Truax 2010). When Truax composed this piece in the early 1990s, it was presumed in psychoacoustics and psychology that pitch was the greatest determinant of gender perception in the voice. Although the composer himself does not refer to any supporting literature from the sciences, his compositional intuitions in terms of gender and psychoacoustic identity very much support such informed hearings. A study conducted by Wolfe et al. (1990) demonstrated that without a visually corresponding figure, for example when speaking on the telephone, a speaker is generally recognised as female when speaking at a fundamental frequency above $160 \mathrm{~Hz}$, roughly E3 or E below middle C, and listeners identify a male speaker when speaking at a frequency below $150 \mathrm{~Hz}$, or $\mathrm{D}$ below middle C (Figure 1). Although the composer has not specifically referred to it, as we will see, Truax's processed voices in Song of Songs often intersect at the ambiguous range between 150 and $160 \mathrm{~Hz}$, particularly when the text takes on an erotically suggestive tone.

Building on the findings of Wolfe et al., Weston et al. (2015) found that, when given a choice between male and female genders, listeners correctly identified the gender of a speaker even when the fundamental speaking pitch was altered, so long as the spectral envelope remained unaffected by pitch-shifting. Weston et al. asked listeners to gauge a speaker's gender in three distinct sources of auditory stimuli. Listeners were introduced to unadjusted recordings of the speakers and also to two examples that had been digitally pitch-shifted to the ambiguous range around $160 \mathrm{~Hz}$ : one using 'pitchsynchronous overlap' that retained the spectral envelope, and another that changed the pitch and distorted the spectral envelope using a 'scalar factor' or asynchronous granular synthesis. They found that when the spectral envelope remained intact listeners could correctly identify the speaker's gender regardless of the spoken pitch level. These studies show that pitch could determine gender perception in the voice even when the spectral envelope is altered, but if unchanged, spectral flux (the rate of spectral change over time) - which is statistically greater in females (Weston et al. 2015: 210) remains the primary determinant of gender perception in the voice. Hence, using a time-stretching process to alter the speaker's inflection disproportionately to the original may impact perception of the speaker's gender. While these findings are useful for determining a basis for the normative gender categories that listeners are

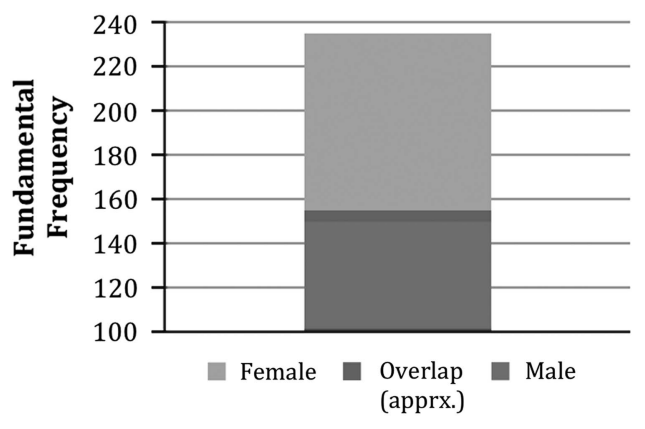

Figure 1. Fundamental frequency and gender perception (Wolfe et al. 1990).

likely to attribute to the voices they hear in Song of Songs, they do not, in my opinion, denote inherited biological traits pertaining to the genders of either speakers or listeners.

Similarly to the techniques employed in the above studies, in Song of Songs, Truax plays with the fundamental speaking pitch of the two speakers through comb filtering and harmonisation to elicit various sonic effects as a deliberate commentary on the relationship between the speakers. He does not employ any pitch-shifting in this piece; instead, he preserves the spectral envelope of his samples and variously extends sample duration without altering pitch content. However, his setting often layers numerous samples of the two speakers on top of one another, sometimes using harmonisation to emphasise other pitches more strongly than the fundamental frequency. Hearing each speaker recite the text in its entirety with the original gendered pronouns, and then layered with several more voices, may cause listeners to question the number of perceived characters in the work, their respective genders, and also, given the erotic tone of the text, the characters' various orientations towards each other.

\section{REDEFINING CATEGORIES}

In my hearing, Truax's setting first establishes binary categories, such as the normative male and female genders or homo- and heterosexual orientations so as to break away from these tropes as the piece progresses. The composer's measured departure from normative constraints, I believe, functions to question and confront a priori categories - including the orientation each speaker takes towards their speaking partner(s) when reciting the erotic text. This blurring of categories fragments and hence reorients the respective identities listeners might attribute to each voice.

For example, in the opening of Song of Songs, Truax establishes the respective identities of the two speakers by introducing the voices with minimal processing. Alexa Woloshyn suggests the opening line, 'Return, return O Shulamite, return, return that we may look 


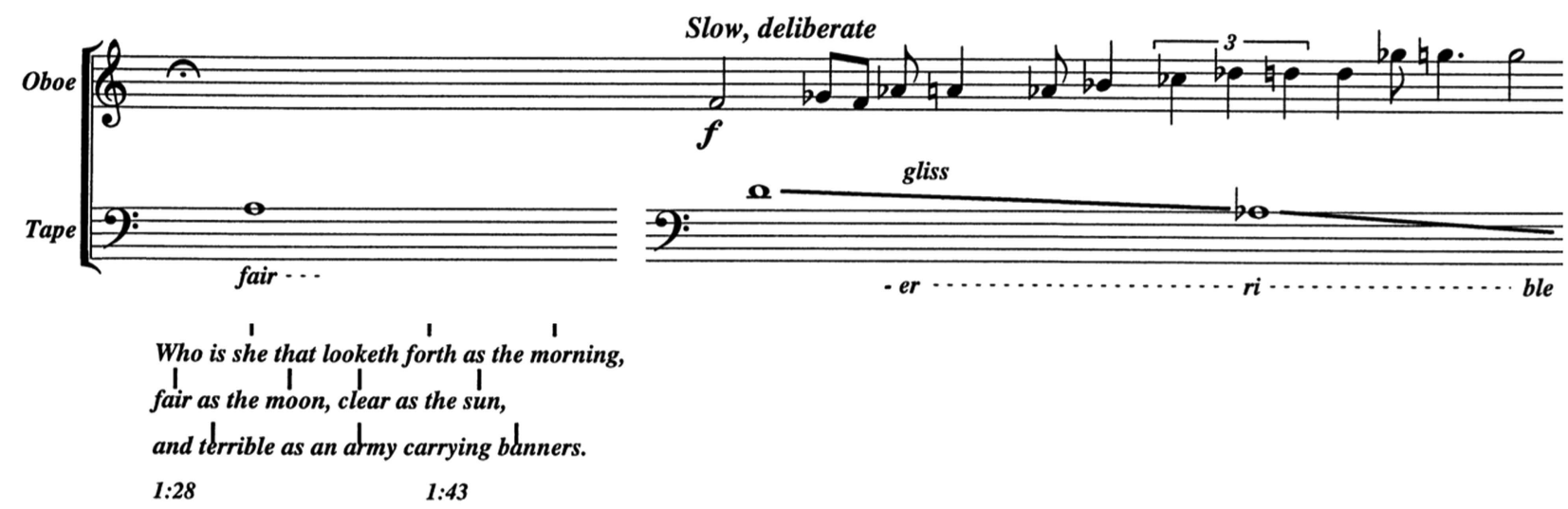

Figure 2. Song of Songs, i: 'Morning', line 5. Song of Songs, i: 'Morning', system 5. Transformation of perceived gender identity and sexual orientation in 'fair' and '[t]errible' voices. Oboe d'amore in A.

upon thee' $(0: 37$ [i, $0: 44$ score $])^{4}$ is recited by both speakers so as to evoke a polyamorous relationship with Shulamite, their female lover (Woloshyn 2012: 159-60). In system $5^{5}$ of the first movement (1:31 [i, 1:28 score]), a man speaks 'Who is she that looketh forth', and we hear a corresponding interjection from a woman (Schiphorst) on the word 'fair' (Figure 2). The prominent pitch of this word sounds around A below middle $\mathrm{C}$, or $220 \mathrm{~Hz}$, with a characteristically feminine upward inflection, as determined by Wolfe et al. and subsequent studies. ${ }^{6}$ The upward inflection of the 'fair' voice brings its fundamental frequency to D or $294 \mathrm{~Hz}$, the pitch at which this voice is met by another voice (Ruebsaat), speaking the word 'terrible', absent the ' $t$ ' attack. Starting here, from the supposed female range (as determined by Wolfe et al.), and then gradually dropping in pitch by exploiting the original downward inflection on the word 'terrible', now made evident by a hundred-fold time-stretching and downward harmonisation, the 'terrible' voice descends through A and G flat to join the oboe for a moment before sliding progressively lower and out of the normative female range.

The mixture of the 'fair' and '[t]errible' voices descends from the female range through what could be inferred as the male range, but quickly departs from the humanspeaking range altogether. This gender ambiguity leads a minute later to the first exclamation of the refrain, 'I am my beloveds and my beloved is mine.' When the line repeats, the two voices return to sound in their respective male and female ranges. After additional declamations, the repeating voices begin progressively to offset one another until eventually a third speaker seems to join the

${ }^{4}$ Times indicate overall running time of the piece according to www. soundmakers.ca/soundstreams-commissions/song-of-songs-barry-truax.

The time cue indicated in the score is included in parenthesis.

${ }^{5}$ In lieu of bar numbers, system numbers are enumerated according to the score, beginning anew with each movement.

${ }^{6}$ In blind listening studies, upward inflection has been observed as a typically female trait, and is encouraged in 'communication feminisation therapy' for individuals transitioning to the female gender (Hancock et al. 1997). duet, another male voice - the same speaker doubled. This additional male partner completes the sentence of the first two speakers, 'I am my beloveds and my beloved is mine. He feedeth among the lilies.' Whereas at first the man and woman may be heard as lovers, soon one voice is transformed to sound ambiguously gendered, mixed with the female voice harmonised both upwards and downwards. Then, after the contraction of the voices back to their respective genders, the doubling of male voices introduces the possibility of a homoerotic relationship among two of the speakers if we take this 'he' as the man's lover. Alternatively, by the end of this phrase, there are three speakers engaged in a perceived polyamorous relationship (Woloshyn 2012: 152).

While sexual identity is presumed to betray an individual persuasion, it is, in actuality, an individual's relation to others that defines one's sexual orientation. Sedgwick (1990: 1-2) theorises the concurrent stability and fluidity of sexual definitions in contemporary Western society in an investigation of the intersection between the fixed homosexual minority (or minoritising view) and the commonalities shared by individuals across a spectrum of possible sexualities on account of gender or other social factors (the universalising view). The fixity of the minoritising view, on the one hand, is important as an identity from which to relate and refer, but, on the other hand, the presumed stasis of sexuality - that individuals should be grouped together only on account of what arouses them sexually - limits the political potential of identification across many more articulations of sexuality. In distinction from Woloshyn, whose analysis remains faithful to Truax's categorical separation of male/female and homo-/heterosexual identities, my analysis views such identities not as inversionally opposite categories but as relationships determined by momentary orientation.

\section{SHARED TERRITORY}

In Song of Songs, Truax disguises the process of transformation, such that the original and processed 

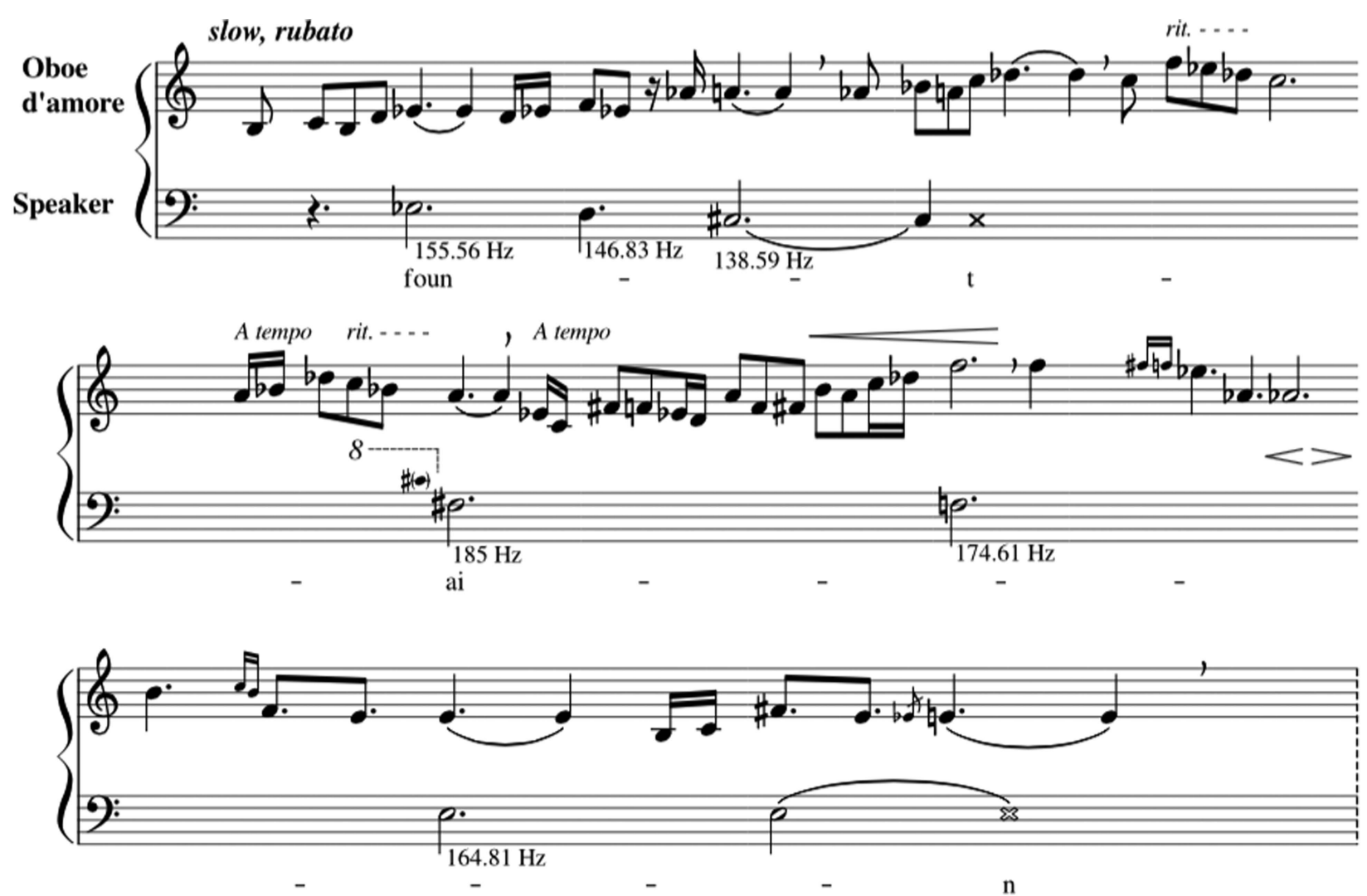

Figure 3. Song of Songs, ii: 'Afternoon', systems 3-5. This transcription shows the strongest sounding fundamentals in the bass clef, the time-stretched 'fountain' sounding in the ambiguous register, in a range around E flat ${ }^{3}$, or $155.5 \mathrm{~Hz}$. X's on systems 3 and 5 indicate the distortion caused by harmonising the consonants ' $t$ ' and ' $n$ '. Oboe d'amore notated at concert pitch.

sources sound simultaneously, thereby bridging associations between recognisable sounds and their transformed counterparts. Such pairing can easily bring about false cognates; meaning, similar sounding sounds may originate from different sources. In the second movement, 'Afternoon' (Figure 3), we see an example of time-stretching and harmonisation that introduces a change of identity and an instance in which the fragmented voice alters the perceived number of speaking personae. The male speaker enters as a recognisable or determinately male voice reciting the text 'A garden enclosed is my sister, my spouse, a spring shut up, a fountain sealed' (4:52 [ii, 0:52 score]). Here the sample is only minimally time-stretched and retains its spectral envelope. At the oboe d'amore's entrance, the word 'fountain' is repeated, this time by the female speaker, and subjected to heavy distortion, granulated and harmonised (both upwards and downwards) at a time-stretched ratio of 100:1 (Truax 2010). Interestingly, the pitches of the time-stretched 'fountain', which emerge through a harmonisation of Schiphorst's voice, are the same frequency as Ruebsaat's initial recitation of the word 'fountain' directly preceding the stretched passage - both sounding in the ambiguous register at a range around $\mathrm{E}^{-\mathrm{flat}^{3}}$ or
$155.5 \mathrm{~Hz}$, thereby blurring any contrast of the two speakers as well as their perceived gender identities. In this example, Truax introduces timbre and pitch ambiguity precisely when the speaker's identity might determine their orientation towards a partner. In reciting the same text, a bond is formed between background and foreground voices, and because the gender identity of the background voice is ambiguous, their relationship becomes uncertain. Neither an opposite-sex nor a samesex partner can be fully ruled out.

The two-part texture here occasionally fragments into a chorus of many more voices, for example in system 4, when $F$ sharp in the lower voice is met also with $C$ sharp, a fifth plus an octave higher. ${ }^{7}$ Truax employs this technique of harmonisation frequently in the piece, in places where the text and voice are recognisable to provide an opportunity for attentive listeners to associate these more ambiguous background streams with time-stretched

\footnotetext{
${ }^{7}$ The composer enriches the sound by overlaying many more grains than in the original, thus adding to the harmonic spectrum, which he harmonises at a ratio of 4:2 (an octave below), 4:5 (a major third above), 4:6 (a perfect fifth above), and 4:12 (an octave plus a perfect fifth above). So, for example, the first note $\mathrm{E}$ flat sounds both at the fundamental (4) and one octave below, at harmonic 2, though I have not notated octave doubling.
} 
voices. Listeners acquainted with granular synthesis and time-stretching will likely also recognise the voice given its timbre and the distortion caused by harmonising the unvoiced consonants ' $t$ ' and ' $\mathrm{n}$ ' (represented by $\mathrm{X}$ note heads in my transcription) - not coincidentally recalling the sound of the flowing fountain water. The same techniques contributing ambiguity to our perception of the speaker's gender identity also cause some blurring of musical categories. For instance, the initial overlap and subsequent transformation of the two voices (at the word 'fountain') is an occasion when the prominent speaking voice drops into the background to take on a supporting role. The composer likens this 'merging of sonic elements ... [to] the extended metaphor of the original text which compares the Beloved to the richness of the landscape and its fruits' (Truax n.d.).

According to the composer, the blurring between genders occurs primarily on account of the gendered text recited by each speaker, 'sometimes reflecting an opposite sex form of address, and sometimes a same sex form' (Truax 2003: 120). Yet he believes real-time granular synthesis enhances the sexual allusions of the text:

Granular stretching of a voice, by adding a great deal of aural volume to the sound with the multiple layers of grain streams ... often seems to create a sensuousness, if not an erotic quality in the vocal sound. A word becomes a prolonged gesture, often with smooth contours and enriched timbre. Its emotional impact is intensified and the listener has more time to savour its levels of meaning. (ibid.: 119)

The transformation brought on by granular stretching recalls a similar analytical interest invoked in gender and sexuality studies by Sedgwick's term 'transitivity', which she recognises as the 'grounds [from which to find] alliance and cross-identification among various groups' (Sedgwick 1990: 89). Sedgwick notes here a distinction between 'transitive' and 'separatist' tropes of sexuality on account of gender. Whereas members of the latter group insist on separating men and women, advocates of the former acknowledge alliances between groups and across genders on the grounds of shared sexual interests. By deliberately instituting disjunctions or transformations of textual, musical, and gender and sexual identities, more than merely 'blurring' the distinctions between the male and female voices within the music, as the composer acknowledges doing, I find Truax's method of composition exemplifies the transitivity model by simultaneously evoking both man and woman in the same vocal range. Granularity also causes the woman's voice to sound huskier, thereby departing from the breathy quality typically attributed to women (Ingleton 2016: 80), and therefore further cementing a connection in both pitch and timbre to the supported (male) speaking voice as well as to the more-heavily granulated Monk's song and cicadas in the background. By the end of the A tempo (5:28 [ii, $\sim 1: 16$ score]) the stretched 'fountain' meets the oboe's pitch to fully solidify the music's many contextual registers.

\section{OVERCOMING MUSIC'S 'NEUTER' ENTERPRISE}

Truax attributes the romantic tryst in the third movement, 'Evening', as the height of homoerotic sensuality in Song of Songs on account of its sultry text, extreme stretching of the word 'desire' (12:27 [iii, 3:38 score]), and a greater frequency of same-sex pairings (Truax 2003: 119-20). Yet, in my opinion, the fourth movement, 'Night and Daybreak', is more exemplary of the music-historical context in which the work was written. Here (Figure 4), a gender ambiguous vocoder-type voice awakens their lover calling: 'My beloved spoke and said to me: Rise my love, my fair one and come away' (15:40 [iv, 1:58 score]). Truax (2010) labels this line a 'duet' in the production score, as both speakers repeatedly recite the line in counterpoint. Chanting alternately therefore draws timbral similarities between the two voices on account of their similar processing through comb filters, while still maintaining the identifying timbral qualities of each gender. In this way, the passage insists simultaneously on difference and sameness.

The lower vocoder voice sounds alternately on the pitches E flat and B flat, where the impulse provides the music's rhythmic propulsion. Through alternation, redundancy forces the suspension of functional harmony, not unlike the accompaniment in Laurie Anderson's O Superman (1981) (McClary 2002: 142).

Truax's Song of Songs shares more than a few features with $O$ Superman. Both reinterpret biblical texts, but more than this, Truax's observations on personal voice and absence compare easily to Anderson's text, in which she states in the opening line, 'This is not a story my people tell. It's something I know myself' (ibid.: 132). Sharing an interest to push beyond tradition, both Truax and Anderson seem to rewrite history in their respective retellings of biblical stories. Anderson's recitation paraphrases the story of Adam and Eve from the woman's perspective, while Truax's Song of Songs preserves gendered pronouns to subvert heteronormative assumptions common in the text's historical reception.

Beyond textual considerations, the works elicit bodily concerns, as both use electronic means to challenge the performers' respective gender identities. Attending to Anderson's voice, Susan McClary's analysis of $O$ Superman recognises the importance of the perceived 'physical source of sound' in this piece (ibid.: 136). As the composer herself stands on stage to declaim the story as she has rewritten it, Anderson places her body actively and conscientiously in a 

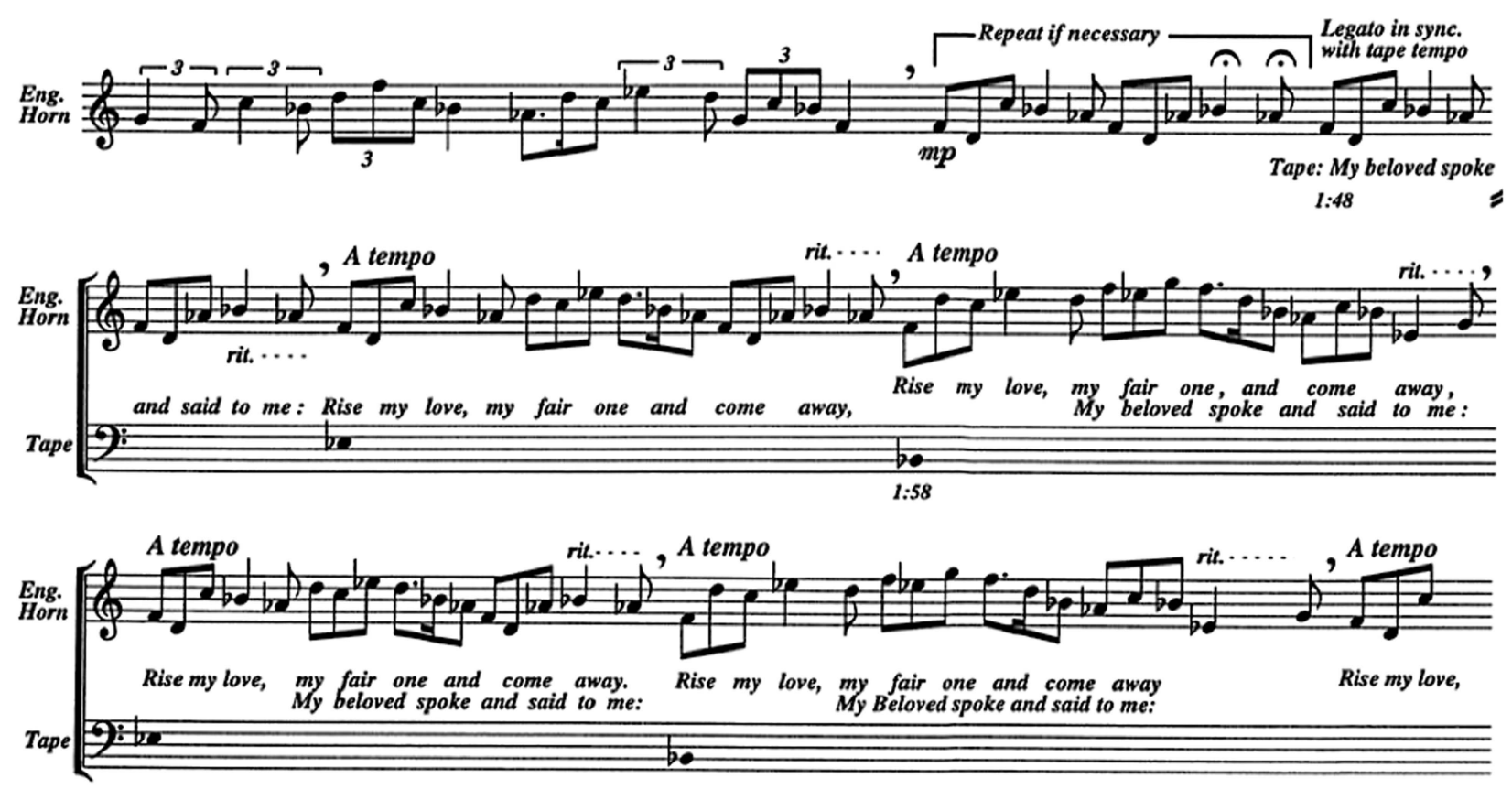

Figure 4. Song of Songs, iv: 'Night and Daybreak', systems 7-9. Ambiguously gendered voices, as if spoken through a vocoder, notated in the bass clef. English horn in F.

performing role. But, according to McClary, although Anderson's female body appears to us on stage, she uses vocoders to perform vocal androgyny so as to resist the frequent scrutiny often inflicting the female body as spectacle. ${ }^{8}$ McClary writes, 'Laurie Anderson's music is multiply charged ... It is electronically saturated at the same time as it insists on the body' (ibid.: 138). This, she says, contrasts with the neutrality with which music is generally regarded - what she terms, its 'neuter' enterprise (ibid.: 139). In a similarbut-opposite tactic, I see Truax denying the visually corresponding bodies of his performers, so as to leave room for ambiguity. Truax's work, like Anderson's, confronts music's presumed 'neuter' presence by simultaneously insisting on the gendered voice while also raising questions as to how categories of gender are typically defined in musical contexts. Like Anderson, Truax breaks away from the compositional mould typically assigned to his gender: he is a male composer who embraces sexual imagery, but not by way of the common misogynist representations all too prevalent in the Western musical canon (McClary 1989: 74).

This comparison of Truax's music to Anderson's shows the transitivity of the universalising view. Both examples confront established tropes of gender perception and music with some similar methods and some methods that are less so. Anderson transforms the visible female body with the androgynous voice,

\footnotetext{
${ }^{8}$ Similar to Truax's Song of Songs, in 'O Superman' Anderson uses harmonisation to populate the background 'chorus' while speaking through a vocoder (Anderson 2016).
}

and Truax emphasises the elasticity of the voice - and its transformative potential - in a habitual stretching and retraction of the common markers of gender in sound. In both works, the text, vocal quality and role of the voice (whether supporting or supported) are inseparable from the music and the world in which that music sounds.

Significantly, Song of Songs not only touches on the social and psychological levels 'indirectly' related to the music (Truax 1994a: 185), but it engages with the musical climate of the time, as evinced by the previous comparison to $O$ Superman. Additionally, the work draws also on the context of the composer's own oeuvre - many of its so-called external associations having been made in other pieces. For example, Beauty and the Beast (1989) features the oboe d'amore and English horn in a story-telling role, similar to how the instrument in Song of Songs seems to elongate the lines of the story by serving as a mediating presence between the internal world of the speakers and the external context of live performance. This instrumental mediation is not unlike Wings of Fire (1996) and Androgyne, Mon Amour (1997), in which an erotic text refers to a 'personified' musical instrument played in each piece respectively by a female cellist and a male double bass player (Truax 2000: 122). The personified instrument thus enriches the ineffable resonances of 'abstract' music with the emotional realm - the listener's inner psychology - as when in Song of Songs the pitches of the processed background and live foreground cross (1:31 [i, 1:28 score]), or when the instrument is synchronised with the electronic part (5:28 [ii, 1:16 score] 
and 9:41 [iii, 0:44 score]). In Basilica (1992), Truax extends the sound of chiming bells through timestretching so that their resonances invoke the human voice. Likewise, in the second movement of Song of Songs, the Monk's voice is overlaid with monastery bells recognisable from the previous movement and stretched to blur the distinction between the two sources but also to immerse them, together with the processed voices of the speakers, in the rich environmental soundscape of the context in which the work is imagined to take place.

\section{CONCLUSION}

Addressing gender in music can be a complicated task. On the one hand, we do not wish to reduce the complex relationships, both musical and erotic, emerging in Song of Songs by identifying its sounds with either a female or a male speaker. But, on the other hand, we threaten losing some aspect of the experience by omitting a discussion of gender and its implications for musical listening. According to Truax, it is often assumed that music's social level 'include[s] all of the material aspects of the context surrounding the musical performance that only indirectly affect it' (1994a: 185, emphasis added), thereby situating the social context in excess to a work's musical relationships. Conversely, his compositional strategy aims to maintain a connection between what is 'musically interesting' and 'the audience's cultural awareness' (ibid.: 186). What I find compelling about Truax's music is the manner by which he draws attention to difference, to gender identity and to sexual orientation while simultaneously diminishing the centrality of normative categories, whether the binary man/woman, gay/ straight categories or the typical musical oppositions between melody and harmony, and between timbral profiles and harmonic spectra.

Finally, it is not enough to acknowledge the blurred boundaries between hidden virtual sources and the live instrumentalist, or the frayed edges of the sample and its no longer recognisable processed counterpart, but Song of Songs is significant in its use of the gendered voice to address and comment on the sexual fluidity of the characters. While the gender of each speaker may at first be associated with one or the other gender, male or female, Song of Songs quickly teaches its listeners that such categories are neither reliable nor stable - not within the work and not in the world beyond.

\section{REFERENCES}

Anderson, L. 2016. How We Made Laurie Anderson's O Superman. The Guardian, 19 April. www.theguardian. com/culture/2016/apr/19/how-we-made-laurie-andersono-superman (accessed 10 August 2016).

Barthes, R. 1977. The Grain of the Voice. In S. Heath (trans.) Image, Music, Text. London: Fontana Press.
Bosma, H. 2003. Bodies of Evidence, Singing Cyborgs and Other Gender Issues in Electrovocal Music. Organised Sound 8(1): 5-17.

Bosma, H. 2013. The Electronic Cry: Voice and Gender in Electroacoustic Music. $\mathrm{PhD}$ thesis, University of Amsterdam.

Bradby, B. 1993. Sampling Sexuality: Gender, Technology and the Body in Dance Music. Popular Music 12(2): 155-76.

Butler, J. 1988. Performative Acts and Gender Constitution: An Essay in Phenomenology and Feminist Theory. Theatre Journal 40(4): 519-31.

Carr, D. 2000. Gender and the Shaping of Desire in the Song of Songs and Its Interpretation. Journal of Biblical Literature 119(2): 233-48.

Cavarero, A. 2005. For More Than One Voice: Toward a Philosophy of Vocal Expression. Stanford: Stanford University Press.

Connor, S. 2000. Dumbstruck: A Cultural History of Ventriloquism. Oxford: Oxford University Press.

Connor, S. 2012. Panophonia. Lecture delivered at the Pompidou Centre, 22 February. www.stevenconnor.com/ panophonia/panophonia.pdf (accessed 14 March 2016).

Dunn, L. C. and Jones, N. A. 1994. Embodied Voices: Representing Female Vocality in Western Culture. Cambridge: Cambridge University Press.

Emmerson, S. 2007. Living Electronic Music. Aldershot: Ashgate.

Fox., M. V. 1985. The Song of Songs and the Ancient Egyptian Love Songs. Madison, WI: University of Wisconsin Press.

Hancock, A., Colton, L. and Douglas, F. 1997. Intonation and Gender Perception: Applications for Transgender Speakers. Journal for Voice 28(2): 203-9.

Ingleton, H. 2016. Recalibrating Fundamentals of Discipline and Desire Through the Automatic Music Tent. Contemporary Music Review 35(1): 71-84.

Kane, B. 2014. Sound Unseen: Acousmatic Sound in Theory and Practice. Oxford: Oxford University Press.

McClary, S. 1989. Terminal Prestige: The Case of AvantGarde Music Composition. Cultural Critique 12: 57-81.

McClary, S. 2002. [1991] Feminine Endings: Music, Gender, and Sexuality. Minneapolis: University of Minnesota Press.

Peraino, J. 2006. Listening to the Sirens: Musical Technologies of Queer Identity from Homer to Hedwig. Berkeley: University of California Press.

Sedgwick, E. 1990. Epistemology of the Closet. Berkeley: University of California Press.

Smalley, D. 1993. Defining Transformations. Interface 22: 279-300.

Sofer, D. 2016. Making Sex Sound: Erotic Currents in Electronic Music. PhD thesis, University of Music and Performing Arts, Graz.

Truax, B. 1985. The PODX System: Interactive Compositional Software for the DMX-1000. Computer Music Journal 9(1): 29-38.

Truax, B. 1988. Real-Time Granular Synthesis with a Digital Signal Processor. Computer Music Journal 12(2): 14-26.

Truax, B. 1990. Composing with Real-Time Granular Synthesis. Perspectives of New Music 28(2): 120-34.

Truax, B. 1992. Electroacoustic Music and the Soundscape: The Inner and Outer World. In J. Paynter, T. Howell, R. 
Orton and P. Seymour (eds.) Companion to Contemporary Music Thought. London: Routledge.

Truax, B. 1994a. The Inner and Outer Complexity of Music. Perspectives of New Music 32(1): 176-93.

Truax, B. 1996. Soundscape, Acoustic Communication and Environmental Sound Composition. Contemporary Music Review 15(1-2): 49-65.

Truax, B. 2000. The Aesthetics of Computer Music: A Questionable Concept Reconsidered. Organised Sound 5(3): 119-26.

Truax, B. 2001. Acoustic Communication, 2nd edn. Westport, CT: Greenwood Press.

Truax, B. 2003. Homoeroticism and Electroacoustic Music: Absence and Personal Voice. Organised Sound 8(1): $117-124$.

Truax, B. 2008. Soundscape Composition as Global Music: Electroacoustic Music as Soundscape. Organised Sound 13(2): 103-9.

Truax, B. 2012. Sound, Listening and Place: The Aesthetic Dilemma. Organised Sound 17(3): 193-201.
Truax, B. n.d. Granulation of Sampled Sound. www.sfu.ca/ $\sim$ truax/gsample.html (accessed 27 November 2017).

Weston, P., Hunter, M., Sokhi, D., Wilkinson, I. and Woodruff, P. 2015. Discrimination of Voice Gender in the Human Auditory Cortex. NeuroImage 105: 208-214.

Wolfe, V., Ratusnik, D., Smith, F. and Northrop, G. 1990. Intonation and Fundamental Frequency in Male-Female Trans-sexuals. Journal of Speech and Hearing Disorders 55: 43-50.

Woloshyn, A. 2012. The Recorded Voice and the Mediated Body in Contemporary Canadian Electroacoustic Music. $\mathrm{PhD}$ thesis, University of Toronto.

\section{DISCOGRAPHY AND MEDIA}

Truax, B. 2010. Documentation DVD \#3. CSR-DVD 1001. Truax, B. 1994b. Song of Songs (1992). On Song of Songs: Computer and Electroacoustic Music by Barry Truax. Burnaby, Canada: Cambridge Street Records, CSR-CD 9401. 